\title{
A Comparison of Wireless Devices for Terahertz Imaging Applications
}

\author{
Camille Merlin S. Tan ${ }^{1}$, Lawrence Materum ${ }^{1,2}$ \\ ${ }^{1}$ De La Salle University, Philippines \\ ${ }^{2}$ Tokyo City University, Japan \\ camille_merlin_s tan@dlsu.edu.ph
}

Received: May 6, 2021. Received: October 30, 2021. Accepted: November 12, 2021. Published: December 6, 2021.

\begin{abstract}
As technology advances, notable scientific research accomplishments have been made. Terahertz (THz) waves have been seen to have endless potential applications that could further improve the current limitations of other frequency bands for imaging applications. Currently, THz waves display great potential in various applications due to their noninvasive and nonionizing features. However, the $\mathrm{THz}$ band has not been technically well established. This paper focuses on a comparative survey of the current methods applied in THz imaging in the field of medical and industrial security applications. Different types of methods, findings, advantages, and challenges of surveys ranging from 2016 to 2021 were discussed for both medical and industrial security applications to deepen the understanding of the latest trends, research, and technologies to have efficient $\mathbf{T H z}$ imaging systems.
\end{abstract}

Keywords: Industrial security applications, medical applications, noninvasive and nonionizing features, terahertz imaging.

\section{INTRODUCTION}

Multiple-input multiple-output (MIMO) refers to a wireless technology that uses several transmitters and several receiver antennas to transfer various data simultaneously, making the communication more efficient [1-3]. There are different types of MIMO configurations such as $2 \times 2,3 \times 3,4 \times 4,8 \times 8$ MIMOs [4]. The higher the number of antennas in a system, the more data can be transferred simultaneously, improving the overall performance. Although higher configuration MIMO antennas generally perform better, it also depends on some environmental factors. Therefore, the same antenna would not perform precisely at the same efficiency when placed on different locations [5-6].

Figure 1 [4] shows a typical single input single output (SISO) wireless communication system. SISO is the most straightforward antenna technology. It refers to a wireless communication system in which one transmitter antenna and one receiver antenna are used. SISO is commonly used in applications such as satellite, TV, radio, code division multiple access (CDMA), and Global System for Mobile Communications (GSM) systems [7-8]. The main advantage of SISO is its simplicity. It does not require any further processing for different types of diversity. The main advantage of a SISO system is that it is straightforward to design while it is low-cost compared to other types of systems $[8]$.
However, since it is simple, it is susceptible to issues caused by multi-path effects in some environments with several buildings and hills, leading to a scattered wavefront, which affects the signal to undergo several paths before reaching the target receiver, the late arrival of the scattered signal can cause signal fading and picket fencing. When applied in digital communication systems, it causes slow data speed and low efficiency.

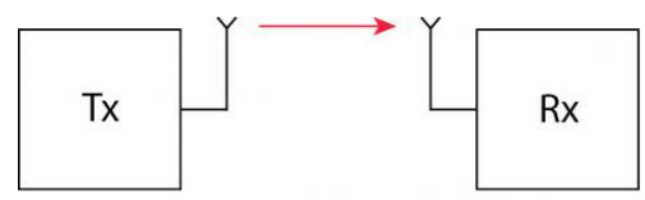

Figure 1. Single-input Single-output (SISO) Wireless Communication System [4]

Single input multiple output (SIMO), multiple input single output (MISO), and MIMO are the methods used to increase and reduce the data speed and data error [4], respectively. SIMO, MISO, and MIMO techniques have three main advantages over SISO [9]. First, they do not require a clear line of sight because they have much stronger signals. The signals can bounce and reflect to the receiver. Second, they can transfer large amounts of data simultaneously faster, especially MIMO, since it can handle greater throughputs. Third, it contains more data streams. It can improve the quality of video and sound content and lessen the chance of having lost data packets [9]. Among all types of systems, MIMO systems are the most complex at the same time. They carry significant capacity. They also have a wide range of applications. For example, transmission can be done through various spatial domains when spatial multiplexing is applied. MIMO systems are generally used in most advanced wireless communication systems such as Third Generation Network (3G), Fourth Generation Network (4G), wireless access Mode (WAM), wireless local area network (WLAN), and wireless metropolitan area network (MAN). The main advantage of the MIMO system is that it performs the best in terms of efficiency and throughput [8]. While the main disadvantage of MIMO is that it requires high-cost radio frequency (RF) modules since it uses several antennas. Thus, some antenna selection technique research is being done to reduce the cost as much as possible. 
Figure 2 [4] shows the MIMO wireless communication system.

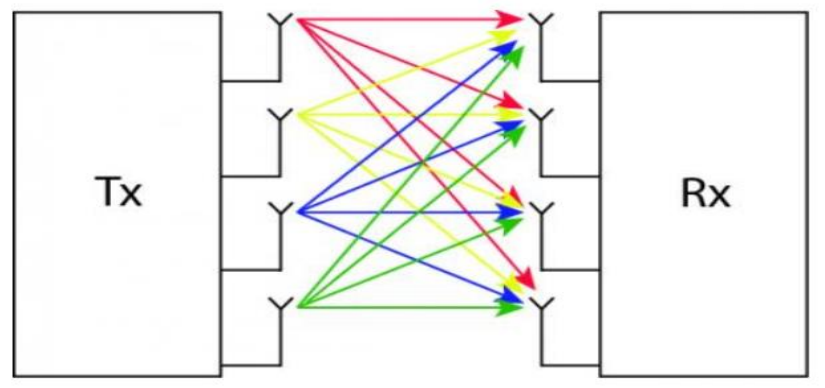

Figure 2. Multiple-input Multiple-output (MIMO) Wireless Communication System [4]

Other than obstructions, another factor that significantly worsens the signal quality in wireless communication is the environmental conditions such as lightning, rainfall, thunderstorms, and geographical positions, affecting the signal quality. It affects the signal-to-noise ratio (SNR) and its error rate, making the signal prone to fading. Therefore, different types of diversity are applied to help stabilize the communication link between the transmitter and the receiver to improve the performance while reducing the error rate [10].

There are three main diversity types available in MIMO systems to enhance the quality of communication. These are time, frequency, and space diversity. Time diversity transmits the information at different times by using other time slots and channel coding. For frequency diversity, it uses different frequencies to transmit information through various channels or Orthogonal Frequency Division Multiplexing (OFDM) technologies. OFDM is commonly used in broadband communications systems because it can maximize the use of a channel compared to other data transmission methods available [8]. For space diversity, it uses different antenna positions to improve the different radio paths.

Furthermore, there are two main formats for MIMO, namely spatial multiplexing and spatial diversity. By using spatial multiplexing, more data capacity can be achieved by using several paths to carry the data traffic. On the other hand, spatial diversity is used to improve the SNR and reliability of the system in terms of signal fading [10].

With the help of MIMO wireless communications, it can increase channel capacity while following Shannon's law. As the number of transmitter and receiver antenna pairs increases in a communication system, it can increase the channel throughput linearly, making MIMO technology one of the most important wireless technology. Nowadays, spectral bandwidth is becoming more and more important in radio communications systems. Antenna technologies like MIMO are necessary to use the available bandwidth more efficiently and effectively [10].

To summarize, there are four critical parameters in communications systems, namely bit error rate (BER), throughput, signal transmission process, signal quality at the receiver side. For MIMO systems, the BER is maximized because several antennas are used in both transmitter and receiver end. While the throughput in MIMO systems has the most significant capacity among all other systems, making it have an extensive range of applications. The diversity method is applied in the signal transmission process since there are several antennas on both the transmitter and receiver sides. While for the signal quality at the receiving side has the best signal quality and diversity gain because the signal can be transmitted through various spatial domains by using spatial multiplexing [8]. Therefore, the MIMO system shows a strong potential for future wireless communication systems. It provides the least fading, maximum throughput, and maximum data rate.

The terahertz $(\mathrm{THz})$ band refers to a portion of the electromagnetic spectrum with frequency ranging from 0.1 $\mathrm{THz}$ to $10 \mathrm{THz}$, with a wavelength of $3 \mathrm{~mm}$ to $30 \mu \mathrm{m}$. These frequencies are in between the millimeter and infrared frequencies [11-13]. The THz frequency range is commonly known as the $\mathrm{THz}$ gap because this section of the electromagnetic spectrum is the least studied frequency range [13-14]. It displays excellent potential for the next generation of wireless communication applications because it can use a wide range of unused bandwidth [15]. At present, the millimeter-wave (mm-wave), whose frequency ranges from $30 \mathrm{GHz}$ to $300 \mathrm{GHz}$, provides multiple-gigabit-per-second (Gbps) data rates for $5 \mathrm{G}$ in mobiles systems. However, the currently used mm-wave experiences difficulties in propagation loss due to significant signal attenuation of electromagnetic waves molecule absorption. In terms of mobile communications, the $\mathrm{THz}$ frequency can also send wide bandwidth signals between base stations, just like the $\mathrm{mm}$-wave. Moreover, the THz frequency band can be applied in whisper radio applications, including wireless personal area networks (PANs) and nanosensors [15]. The interaction between THz radiation and an object is mainly dependent on the state of an object. For gasses, the intensity of interaction rises significantly for frequencies after the microwave band. It peaks at the $\mathrm{THz}$ band then drastically falls as it approaches the infrared band. While for liquids and solids, the vigorous motions of molecules lead to a broad $\mathrm{THz}$ spectrum [16]. Moreover, the $\mathrm{THz}$ frequency is generally flexible for imaging security applications based on spectroscopy since the $\mathrm{THz}$ light can interact with numerous types of materials. Figure 3 [9] shows the location of the $\mathrm{THz}$ band in the electromagnetic spectrum. 

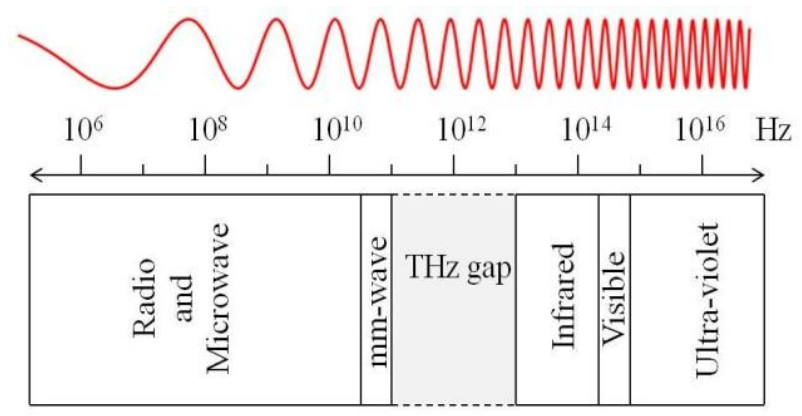

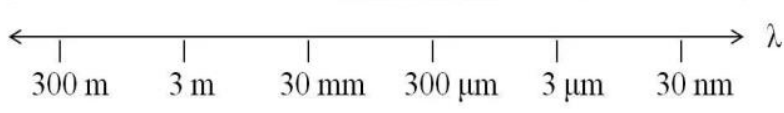

Figure 3. Schematic Diagram of the Electromagnetic Spectrum [9]

Nowadays, researchers from various fields such as electronics, optics, chemistry, and physics have been investigating the $\mathrm{THz}$ band [17]. One of the significant advantages of $\mathrm{THz}$ waves is that it is nonionizing [18]. Thus, several materials that block both visible and infrared (IR) spectra appear transparent in the terahertz region. This property means that $\mathrm{THz}$ waves can see through several types of opaque materials such as cloth, walls, plastics, polyethylene, polyester, and some types of liquid materials. In addition, some chemical substances display their characteristic spectral lines only in the $\mathrm{THz}$ range between 1 $\mathrm{THz}$ to $3 \mathrm{THz}$, which can offer valuable data and information regarding its structure for performing chemical analysis [18]. Therefore, compared to the microwave frequency, the $\mathrm{THz}$ frequency allows us to achieve an excellent spatial resolution for quality imaging. Moreover, $\mathrm{THz}$ waves' unique characteristics make them more attractive than X-rays and near-infrared radiation (NIR). Unlike X-rays, THz waves are safe and harmless to living creatures such as people, animals, and plants, due to their nonionizing and noninvasive feature, it is also the main reason why they are commonly used in medical applications such as detection of skin problems, body imaging and dental imaging [18].

Currently, several areas show potential applications for $\mathrm{THz}$ applications, such as $\mathrm{THz}$ imaging, $\mathrm{THz}$ quality control, $\mathrm{THz}$ wireless communications, and $\mathrm{THz}$ science [11]. For $\mathrm{THz}$ imaging, it is commonly used in medical and industrial security applications. A $\mathrm{THz}$ wave is used in medical applications to penetrate up to hundreds of micrometers in human tissues [11,18]. It can be used to analyze the upper layer of the human body, such as skin, joints, muscles, and vessels, including dental imaging. While it can be used for item detection for industrial security purposes, it is also beneficial in detecting explosive materials. In semiconductor packaging inspections, it can remotely detect items under metals, ceramics, plastics, and clothes for a distance within several meters $[11,18]$. For wireless communications, it provides high-speed data transmission between wireless local area networks, electronic devices and provides secure communications. Thus, it was able to attract the interest of researchers since it can provide high-speed wireless transmission beyond 5G [11]. For THz science, its application includes spectroscopy of lattice vibrations of crystals and bending of molecules [18]. THz spectroscopy has advantages in analyzing the absorption spectrum of liquid because the waves can be absorbed well [19]. THz spectroscopy is commonly used in biochemical applications such as analyzing protein and deoxyribonucleic acid (DNA) structures. Since it can differentiate between wet and dry substances due to its high-water absorption capabilities, some paper manufacturers also use it to monitor the moisture and thickness of the paper content [11]. Moreover, the $\mathrm{THz}$ frequency range is easy to study meta-materials and plasmonic effects $[11,18]$.

In addition, some applications such as ancient art evaluation use the combination of $\mathrm{THz}$ spectroscopy and imaging to detect image thickness, material type, layers of artwork, and antiquities to analyze an artwork [11]. THz imaging offers information on the painting's underlayers. It is very detailed to the order of tens of microns. Also, both $\mathrm{THz}$ spectroscopy and imaging are very helpful for noninvasive methods of evaluating solid medicines such as tablet coatings and ingredients properties.

Figure 4 [11] shows the original photo of Madonna in Preghiera together with its $\mathrm{THz}$ image using the integrated spectrum between $0.5 \mathrm{THz}$ to $1 \mathrm{THz}$. It can be observed that the intensity in the $\mathrm{THz}$ photo is not uniform, although it seems uniform in the original photo. The $\mathrm{THz}$ imaging is a powerful tool for analyzing an artwork. It shows some features which other evaluation methods cannot see by using an X-ray. It can help determine whether art is original since it can verify the type of material used and the age of the art by looking at its intensity in the $\mathrm{THz}$ image [20]. Chemical analysis and structural analysis are the methods used to analyze artwork. For chemical analysis, it uses Fourier transform to obtain the chemical pigments, fingerprints, and resonances. For structural analysis, some features present in the deeper layer of an image can be seen by reconstructing the image using time of flight data [21].
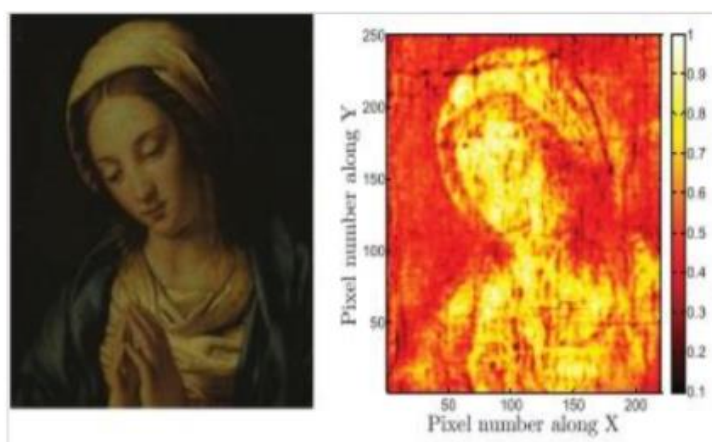

Figure 4. The Original and $\mathrm{THz}$ Photo of Madonna in Preghiera [11]

Many researchers have been studying the $\mathrm{THz}$ band from the last century up to the present. Although there are many potential applications in various fields, $\mathrm{THz}$ waves need to overcome several challenges in order to be applied in the available technologies nowadays. One major issue in applying $\mathrm{THz}$ imaging systems is the high cost of sources and detectors. Although the advancements of technology can make these detectors cheaper to implement, it is still not practical to develop and make them economically beneficial for various applications due to the low acquisition speed 
$[11,22]$. Recently, it has been seen that high-speed systems are possible. However, most of these samples use only a tiny region of $\mathrm{THz}$ waves. The development of the system is very application-specific because it is a must that the sampled subregion matches with the desired signal response [23]. Also, poor SNR is a severe issue for some regions of the $\mathrm{THz}$ spectrum. In addition, one limitation of $\mathrm{THz}$ spectroscopy is that it cannot detect high moisture products with thicknesses more than $1 \mathrm{~mm}$ due to the high absorption rate of $\mathrm{THz}$ radiation in the water [22,24].

According to [22], their study uses very thin skin samples with a thickness of around $1 \mathrm{~mm}$, the slices of skin and lean tissue samples are fragile due to water absorption in the $\mathrm{THz}$ spectrum, and it is almost opaque above $0.7 \mathrm{THz}$. According to [25], one possible solution to this issue is to use $\mathrm{THz}$ imaging reflection. However, there is a possibility that the standing waves may produce image artifacts because of the differences in the optical path length. Moreover, another challenge in $\mathrm{THz}$ spectroscopy is that it is prone to scattering, which plays a vital role in measuring $\mathrm{THz}$ absorption, especially in some materials. Reference [26] examined the scattering effects for the $\mathrm{THz}$ range of $0.2 \mathrm{THz}$ to $1.2 \mathrm{THz}$ using solids such as flour, salt, and Ammonium Nitrate (NH4NO3). The Mie theory is applied in order to allow spectrum differentiation from different sampled materials. Nevertheless, the Mie theory was not able to successfully work on large non-spherical samples.

This paper is organized then as follows. In Section 2, the latest studies and surveys regarding $\mathrm{THz}$ imaging for medical and industrial security are reviewed, tabulated, and discussed. Section 3 discusses the summary and findings of the contents in Section 2. Section 4 contains the conclusion and recommendations of the survey. The last part of the survey discusses limitations in past studies to help future researchers improve the $\mathrm{THz}$ applications in medical and industrial security.

\section{EXISTING STUDIES AND SURVEYS}

\section{A. Industrial Security Applications}

AlNabooda et al. [27] discuss $\mathrm{THz}$ spectroscopy and imaging to detect and identify illicit drugs. This study focuses on the $\mathrm{THz}$ imaging systems, $\mathrm{THz}$ time-domain spectroscopy, and $\mathrm{THz}$ fingerprint absorption spectrum of illicit drugs. Although X-ray and infrared imaging can pass through packages and identify their contents, they still have limitations, unlike THz imaging. For X-ray, it can detect the contents of the package, but it cannot differentiate between pharmaceutical and illicit drugs. On the other hand, IR imaging can differentiate between pharmaceutical and illicit drugs because their spectral fingerprints are in the IR region. However, the main disadvantage of IR is that its accuracy is low due to the high absorption rate of the packaging material. The researchers conducted their experiment by using 20 grams of methylenedioxy-methamphetamine (MDMA) and aspirin samples. All of them were placed in a bag made from polyethylene and inserted into an air-mail envelope. Seven images were recorded, with each having different frequencies. Also, this study discusses the challenges that need to be considered for future development of $\mathrm{THz}$ imaging in security applications, characteristics such as noise level, power, attenuation losses, and real-world compatibility are some of the pointers that must be considered. Results show that the drugs can still be identified using $\mathrm{THz}$ imaging even when they are mixed.

$\mathrm{Lu}$ et al. [28] implement a reflective single-pixel $\mathrm{THz}$ imaging system based on the photoinduced dynamic masks. This study examines three types of THz imaging systems such as time-of-flight measurement of samples with multiple interfaces, noninvasive testing of a hidden object, and spectral identification of chemical substances. Results show that the proposed system could reconstruct a reflective $\mathrm{THz}$ spectral image by combining the inverse Fresnel diffraction (IFD) algorithm with the concept of compressed sensing (CS). In addition, the proposed system was able to identify an object clearly even inside an envelope.

Saini et al. [29] focus on implementing a microstrip patch antenna using denim having a dielectric constant of 1.6 as a substrate for drug and explosive material detection. The antenna was designed and evaluated using the CST Microwave Studio 2014. Its performance is evaluated in terms of directivity, resonant frequency, return loss, gain, impedance bandwidth, impedance, and voltage standing wave ratio (VSWR). Results show that the proposed antenna can detect TNT explosive materials since it achieved good gain, directivity, and impedance values.

Yang et al. [30] focus on implementing a compensation method for high-frequency vibration by range decomposition for aircraft applications because high-frequency vibration is unavoidable in radar imaging. It is an essential factor in the quality of the image, especially in the $\mathrm{THz}$ band, because it has shorter wavelengths, making it very sensitive to highfrequency vibration compared to the conventional radar in the microwave band. This method was evaluated by simulating both the original image of the aircraft with vibration and the image after applying the vibration compensation. Results show that the proposed method performs well, the phase error was compensated, and the azimuth resolution improved significantly.

Liu et al. [31] focus on implementing efficient $\mathrm{THz}$ imaging by applying the concept of compressed sensing (CS). Compressed sensing is a technique of signal sampling and reconstruction, wherein scattered signals can be retrieved easily. CS offers a good solution for both $\mathrm{THz}$ and $\mathrm{IR}$ imaging. CS imaging can decrease the necessary time measurement compared to the usual scanning technique since the $\mathrm{THz}$ imaging requires fewer signal samples for image reconstruction. For modulating the spatial resolution of the $\mathrm{THz}$ beam using a spatial light modulator (SLM), the compressive $\mathrm{THz}$ imaging can execute image compression simultaneously. The proposed technique was evaluated using three experiment types: projector-based CS imaging system, video-rate IR imaging system, and $\mathrm{THz}$ pulse imaging system. Results show that the proposed system obtained a video rate CS imaging at IR frequencies with a pixel size of 96 by 96 pixels with 10 frames per second. 
Sun et al. [32] focus on implementing a $\mathrm{THz}$ imaging system to improve the speed of data collection and achieve imaging with a millimeter-scale resolution by applying a sparse MIMO array. This study discussed the sparse MIMO array design, $\mathrm{THz}$ imaging architecture, multi-channel calibration, and imaging algorithm in detail. The system comprises 16 transmitter channels and 16 receiver channels with a sweep frequency bandwidth of $105 \mathrm{GHz}$. The proposed system was evaluated through actual experiments. The 16 transmitter channels lighten the target consecutively using a stepped frequency signal that ranges from $220 \mathrm{GHz}$ to 325 GHz. At the same time, the 16 receiver channels record the target scattering signal simultaneously by multi-channel ADC and digital signal processing module. After the multi-channel error calibration, the back-projection algorithm was used to reconstruct the $\mathrm{THz}$ images. Results show that the proposed system can produce a high-quality image with millimeterscale resolution. For future research, researchers suggest using linear frequency modulation (FMCW) signals instead of continuous wave stepped frequency to improve the efficiency of the system.

Salmon et al. [33] focus on developing a low-cost $\mathrm{THz}$ detection by converting the $\mathrm{THz}$ radiation into thermal radiation using an IR camera. The primary purpose of this study is to increase the range of an IR camera towards the $\mathrm{THz}$ range since most $\mathrm{THz}$ detectors are expensive, have low spectral selectivity and low sensitivity. In doing this, an emissive layer and a thin layer of $\mathrm{THz}$ absorber are applied. The emissive layer is a suspension of carbon nanotubes (CNT). On the other hand, the THz absorber is a metasurface made up of a metal-insulator-metal (MIM) antenna. It has subwavelength dimensions that display a total absorption of the incident radiation at a resonance frequency. Results show that the proposed system can convert the $\mathrm{THz}$ radiation into thermal radiation, but it needs further study since the broad spectral response is inconsistent.

Table 1. Comparative Survey for Industrial Security Applications

\begin{tabular}{|c|c|c|c|c|}
\hline Key Features & Key Technique & Main Advantages & $\begin{array}{l}\text { Frequency; } \\
\text { Distance }\end{array}$ & Main Challenges \\
\hline $\begin{array}{c}\text { Terahertz imaging and } \\
\text { spectroscopy for } \\
\text { identification of illicit drugs } \\
{[27]}\end{array}$ & $\begin{array}{l}\text { Three different types of } \\
\text { sugar were placed together } \\
\text { inside opaque packagings }\end{array}$ & $\begin{array}{l}\text { High efficiency, the samples } \\
\text { were correctly identified } \\
\text { despite very thick opaque } \\
\text { packaging }\end{array}$ & ---- & $\begin{array}{l}\text { Difficult to identify the type } \\
\text { of drugs especially mixed } \\
\text { chemicals }\end{array}$ \\
\hline $\begin{array}{l}\text { Photoinduced dynamic } \\
\text { mask based reflective } \\
\text { single-pixel terahertz } \\
\text { imaging system combines } \\
\text { CS and IFD [28] }\end{array}$ & $\begin{array}{l}\text { THz imaging system was } \\
\text { applied in spectral } \\
\text { identification, time-of-flight } \\
\text { imaging, and noninvasive } \\
\text { testing }\end{array}$ & $\begin{array}{l}\text { High efficiency, the } \mathrm{THz} \\
\text { image can be reconstructed } \\
\text { precisely from the reflective } \\
\text { signal }\end{array}$ & $1.2 \mathrm{THz}$ & $\begin{array}{l}\text { Distortion of the spectrum is } \\
\text { one of the aspects which } \\
\text { should be considered } \\
\text { carefully }\end{array}$ \\
\hline $\begin{array}{c}\text { THz textile microstrip patch } \\
\text { antenna for TNT explosives } \\
\text { detection [29] }\end{array}$ & $\begin{array}{l}\text { Black denim antenna } \\
\text { substrate is used with a } \\
\text { dielectric constant of } 1.6\end{array}$ & $\begin{array}{l}\text { Minimal return loss, suitable } \\
\text { for both detection of drugs } \\
\text { and TNT explosives }\end{array}$ & $247 \mathrm{GHz}$ & $\begin{array}{l}\text { Two items may be } \\
\text { chemically similar, but } \\
\text { absorption spectra in } \mathrm{THz} \\
\text { are different }\end{array}$ \\
\hline $\begin{array}{l}\text { A method for high- } \\
\text { frequency vibration in } \mathrm{THz} \\
\text { radar imaging based on } \\
\text { dominant scatters [30] }\end{array}$ & $\begin{array}{l}\text { High-frequency vibration } \\
\text { was compensated and } \\
\text { estimated by decomposing } \\
\text { range resolution cell, } \\
\text { containing a single } \\
\text { dominant scatter }\end{array}$ & $\begin{array}{c}\text { Provides high-resolution } \\
\text { imaging }\end{array}$ & $\begin{array}{l}0.44 \mathrm{THz} \\
5 \mathrm{~m}\end{array}$ & $\begin{array}{l}\text { The THz radar system is } \\
\text { susceptible to high- } \\
\text { frequency vibration caused } \\
\text { by short wavelength of THz } \\
\text { wave than microwave band }\end{array}$ \\
\hline $\begin{array}{c}\text { THz imaging with } \\
\text { compressed sensing [31] }\end{array}$ & $\begin{array}{l}\text { A THz pulse imaging } \\
\text { system, video-rate IR } \\
\text { imaging system, and } \\
\text { projector-based CS imaging } \\
\text { system experiments were } \\
\text { performed }\end{array}$ & $\begin{array}{l}\text { High speed and high } \\
\text { efficiency, works well in all } \\
\text { types of experiment settings }\end{array}$ & ---- & $\begin{array}{l}\text { High SNR, high spatial } \\
\text { resolution, and long image } \\
\text { acquisition time was } \\
\text { obtained from a single-pixel } \\
\text { method }\end{array}$ \\
\hline $\begin{array}{l}\text { THz imaging system which } \\
\text { combines the ultra- } \\
\text { wideband and sparse MIMO } \\
\text { array techniques [32] }\end{array}$ & $\begin{array}{l}\text { For improving efficiency, a } \\
\text { linear frequency modulation } \\
\text { signal should be used } \\
\text { instead of stepped frequency } \\
\text { continuous wave }\end{array}$ & $\begin{array}{l}\text { High efficiency and good } \\
\text { image quality with a } \\
\text { millimeter-scale resolution } \\
\text { during actual experiments }\end{array}$ & $\begin{array}{l}272.5 \mathrm{GHz} \\
1.5 \mathrm{~mm}\end{array}$ & $\begin{array}{c}\text { Different delays from each } \\
\text { hardware component led to } \\
\text { unbalance of phases among } \\
\text { the channels }\end{array}$ \\
\hline $\begin{array}{l}\text { THz radiation is converted } \\
\text { into thermal radiation using } \\
\text { an IR camera [33] }\end{array}$ & $\begin{array}{c}\text { combines THz absorber } \\
\text { composed of MIM antenna } \\
\text { and an emissive layer of } \\
\text { CNT }\end{array}$ & Low cost & $142 \mathrm{GHz}$ & $\begin{array}{l}\text { Most THz detectors are } \\
\text { expensive with low spectral } \\
\text { selectivity and sensitivity }\end{array}$ \\
\hline
\end{tabular}




\section{B. Medical Applications}

Abohmra et al. [34] implemented a hybrid gold and graphenebased wearable terahertz antenna for the human body. This study evaluates the performance of the proposed system by comparing the results in free space and on human skin. One of the challenges in antenna design is that human skin absorption makes it difficult to simulate the skin structure precisely. For simulating the signal passing through the skin, the proposed system was tested using two layers of the epidermis and a layer of the dermis. The thickness of human skin varies. It ranges from $0.05 \mathrm{~mm}$ to $1.5 \mathrm{~mm}$ and $1.5 \mathrm{~mm}$ to $4 \mathrm{~mm}$ for the epidermis and dermis, respectively. The human skin is an anisotropic and heterogeneous medium. It is composed of pigments and blood vessels which are widely distributed in depth. For simulations of human skin, experiments generally use three layers of skin as a model, two layers of the epidermis and a layer of the dermis.

The proposed antenna was designed using CST microwave studio 2018. On this design, the antenna applies the chemical potential of $0 \mathrm{eV}$ and a relaxation time of $0.1 \mathrm{ps}$, and the second resonant element used is gold with a thickness of 18 $\mu \mathrm{m}$. Results show that the proposed system could obtain an efficiency of $93 \%$ on free space and an efficiency of $36 \%$ onbody. The antenna has a bandwidth of $120 \mathrm{GHz}$, while it increased to $150 \mathrm{GHz}$ for on-body conditions. Also, the antenna performs well within the range of $1 \mathrm{~mm}$ to $2 \mathrm{~mm}$ from the body's surface. In addition, since the antenna is small and flexible, mixed with good impedance matching, high gain, high bandwidth, high efficiency, it makes it a good choice for short-range $\mathrm{THz}$ communications.

Tokumoto et al. [35] implemented stretchable and flexible Terahertz imagers by integrating the carbon nanotube (CNT) for wearable applications. A flexible $\mathrm{THz}$ imager has gained the attention of many researchers since it can be applied in several industrial fields. Its advantage is that it has a high absorption ratio in broadband THz. Other than CNT, the proposed system also contains some electrodes and substrate films. This study was able to explore the fundamental performances of $\mathrm{THz}$ wave detection. Results show that the proposed system performs well and displays a broad range of possibilities for multiple functional applications in healthcare systems such as skin scanners and monitoring of human body conditions.

Humphreys et al. [36] focus on discussing the current $\mathrm{THz}$ technology, its applications, prospects, and some suggestions to address and improve the $\mathrm{THz}$ imaging applications for medical applications. The study's primary purpose is to improve the THz medical applications while reducing the cost of manufacture compared to the existing systems. There are three main problems in applying the THz band for medical applications: imaging resolution, speed acquisition and signal to noise ratio, tissue differentiation, and spectral database. For $\mathrm{THz}$ imaging to be specialized, beamforming components should be developed. For future research, the researchers plan to develop flexible waveguide delivery systems by applying the concept of corrugated waveguides. However, this type of system is challenging to make it perform efficiently. In addition, making a database containing all of the essential details of biological tissues in the $\mathrm{THz}$ band can be helpful in THz sensing, imaging, and spectroscopy.

Utaki et al. [37] focus on implementing a stretchable $\mathrm{THz}$ detector by combining a thin sheet of polyurethane substrate and a carbon nanotube (CNT) film photodetector for healthcare monitoring. Humans can wear the system. Its usage is to inspect the quality of liquids by examining the changes in the intensity of the blackbody's radiation through liquid solvents as the solute flows. The CNT film arrays with a width of $100 \mu \mathrm{m}$ were modeled. A series of PN junctions were produced on the thin polyurethane substrate using the ultraviolet (UV) laser and vacuum filtration. On each PN junction and direct current (DC) photovoltage response, the photoinduced heat localization is dependent on the number of channel combinations. As the channel increases, the photoinduced heat localization also increases. The proposed system was able to perform efficiently. Some experimental details such as durability, stretchability, and accuracy of liquid sensing were also tested. In addition, this study provides a deeper understanding of stretchable photo-thermal electronics and shows excellent potential for various applications such as pharmaceutical, medical, and industrial applications.

Medvedev et al. [38] focus on implementing a $\mathrm{THz}$ breath sensing complementary metal-oxide-semiconductor (CMOS) based system that uses the human breath to analyze the blood glucose and evaluates airway inflammation of asthma. A comparative study was performed using the $\mathrm{THz}$ sensor and the currently available gas chromatography-mass spectrometry (GC-MS) to gather breath samples. Around 150 breath samples were gathered and analyzed. For each sample, different $\mathrm{THz}$ measurements were performed. The THZ samples show high consistency in dilutions for breath species such as ethanol $(\mathrm{CH} 3 \mathrm{CH} 2 \mathrm{OH})$ and acetaldehyde $(\mathrm{C} 2 \mathrm{H} 4 \mathrm{O})$. Also, breath acetone is strongly correlated with the blood glucose of type 1 diabetes. However, the level of acetone concentration alone cannot determine the blood sugar level. Results show that the proposed system was able to perform efficiently. It can also be applied in various applications such as military, medical, and government health sectors.

Hassanin et al. [39] focus on implementing a new transmission line matrix method for image reconstruction to acquire the shape of an object. The proposed system is based on the concept of both a node and a nonlinear conjugate gradient optimization technique. Various 3-dimensional (3D) node distribution with noise was used to examine the proposed method. The shape of an object was obtained by using a mathematical analysis based on the transmission line matrix method. Results show that the proposed method proves to be efficient for both sensitivity analysis and inverse scattering analysis. Also, it can be applied to very noisy images.

Krishna et al. [40] focus on implementing a 3-layer antenna structure for medical applications. The proposed antenna comprises a graphene patch, 2-dimensional (2D) copper conducting material, and a polyimide substrate. A graphene patch is a transparent high-speed material. It is elastic and has special electronic and mechanical properties that make it highly acceptable for medical $\mathrm{THz}$ imaging. The proposed antennas focus on designing a graphene-based microstrip monopole antenna on the polyimide substrate. There are 9 design parameters considered in the proposed system, namely 
substrate length (Lsub), substrate width (Wsub), substrate thickness $(\mathrm{T})$, patch length $(\mathrm{Lp})$, patch width $(\mathrm{Wp})$, fractal teeth length (GL), fractal teeth width $(\mathrm{Gw})$, feedline length (Lf) and feedline width (Wf) with the following dimensions: $200 \mu \mathrm{m}, 200 \mu \mathrm{m}, 20 \mu \mathrm{m}, 90 \mu \mathrm{m}, 110 \mu \mathrm{m}, 25.5 \mu \mathrm{m}, 11.08 \mu \mathrm{m}$, $60 \mu \mathrm{m}, 8.5 \mu \mathrm{m}$, respectively. The frequency used to evaluate the proposed antenna ranges from $721 \mathrm{GHz}$ to $753 \mathrm{GHz}$. Parameters like voltage standing wave ratio (VSWR), return loss, radiation pattern, gain, directivity, and radiation efficiency were examined. Computer simulations are used to evaluate these parameters using the High-Frequency Structure Simulation (HFSS) tool. Results show that the antenna operates at frequency of $736.90 \mathrm{GHz}$, the obtained values are $\mathrm{VSWR}=1.00$, return loss $=-50.24 \mathrm{~dB}$, gain $=6.62 \mathrm{~dB}$, directivity $=6.89 \mathrm{~dB}$ and radiation efficiency is greater than $95 \%$. Therefore, it is proven that the antenna is well suited for medical imaging applications due to its high efficiency.

Abohmra et al. [41] focus on implementing a graphenebased terahertz antenna for flexible and wearable applications.
The antenna is composed of a graphene patch, dielectric substrate, and ground plane. For improving the flexibility and fitness of the antenna, a graphene material is used in both the transmission feed line and the ground plane. The proposed system was evaluated by testing all the possible resonant frequencies by changing the relaxation time between $0.1 \mathrm{ps}$ to $0.8 \mathrm{ps}$ and the graphene chemical potential between $0.1 \mathrm{eV}$ to $0.4 \mathrm{eV}$. In addition, the researchers use various flexible substrates to evaluate the effect of the substrate material on the antenna's performance. Results show that the proposed system can resonate at various frequencies of $4.546 \mathrm{THz}$, $4.636 \mathrm{THz}$, and $5.347 \mathrm{THz}$ in the $\mathrm{THz}$ band by altering the relaxation time and chemical potential. For changing the chemical potential, the bandwidth increases from $199 \mathrm{GHz}$ to $314 \mathrm{GHz}$. The radiation pattern depends on the chemical potential, the side lobe increases, and antenna directivity decreases by altering the chemical potential.

Table 2. Comparative Survey for Medical Applications

\begin{tabular}{|c|c|c|c|c|}
\hline Key Features & Key Technique & Main Advantages & $\begin{array}{l}\text { Frequency; } \\
\text { Distance }\end{array}$ & Main Challenges \\
\hline $\begin{array}{l}\text { Hybrid gold and graphene- } \\
\text { based wearable antenna [34] }\end{array}$ & $\begin{array}{l}\text { Represented human skin } \\
\text { using three layers }\end{array}$ & $\begin{array}{l}\text { High efficiency, high } \\
\text { bandwidth, and high gain }\end{array}$ & $\begin{array}{l}150 \mathrm{GHz} \\
1 \mathrm{~mm} \sim 2 \mathrm{~mm}\end{array}$ & $\begin{array}{l}\text { Challenging to simulate } \\
\text { skin structures precisely due } \\
\text { to the natural absorption } \\
\text { behavior of the human skin }\end{array}$ \\
\hline $\begin{array}{l}\text { Stretchable imaging-based } \\
\text { wearable antenna for bio- } \\
\text { monitoring applications [35] }\end{array}$ & $\begin{array}{l}\mathrm{CNT} \text { is used to have a high } \\
\text { absorption ratio }\end{array}$ & $\begin{array}{l}\text { Provides a wide range of } \\
\text { applications for healthcare } \\
\text { systems }\end{array}$ & $1 \mathrm{~mm} \sim 2 \mathrm{~mm}$ & $\begin{array}{l}\text { Challenging to achieve } \\
\text { highly reliable and } \\
\text { noninvasive biological } \\
\text { monitoring of human bodies }\end{array}$ \\
\hline $\begin{array}{l}\text { A stretchable detector that } \\
\text { combines polyurethane } \\
\text { substrate and CNT film } \\
\text { photodetector for liquid } \\
\text { quality inspection [37] }\end{array}$ & $\begin{array}{l}\text { Series of PN junctions are } \\
\text { designed to capture the } \\
\text { blackbody radiation clearly }\end{array}$ & $\begin{array}{l}\text { Broad photo-absorption } \\
\text { characteristics }\end{array}$ & $1 \mathrm{~mm} \sim 3 \mathrm{~mm}$ & $\begin{array}{l}\text { Challenging to see changes } \\
\text { in the intensity of the } \\
\text { blackbody radiation through } \\
\text { liquid solvents as the target } \\
\text { solutes flow }\end{array}$ \\
\hline $\begin{array}{l}\text { Analyzes blood glucose of } \\
\text { human-based on the } \\
\text { chemical composition of } \\
\text { breath [38] }\end{array}$ & $\begin{array}{l}\text { A survey was done by } \\
\text { comparing collected } \\
\text { samples from the proposed } \\
\text { system and existing GC-MS }\end{array}$ & $\begin{array}{l}\text { Low cost and portable } \\
\text { sensor }\end{array}$ & $250.44 \mathrm{GHz}$ & $\begin{array}{l}\text { Several studies were } \\
\text { reviewed before being able } \\
\text { to show the analytical } \\
\text { capabilities of the THz } \\
\text { chemical sensors }\end{array}$ \\
\hline $\begin{array}{l}\text { Transmission line matrix } \\
\text { method for image } \\
\text { reconstruction [39] }\end{array}$ & $\begin{array}{l}\text { Developed a method based } \\
\text { on node and a nonlinear } \\
\text { conjugate } \\
\text { technique }\end{array}$ & $\begin{array}{l}\text { Efficient for sensitivity, } \\
\text { inverse scattering analysis, } \\
\text { and noisy images }\end{array}$ & ---- & $\begin{array}{l}\text { Time-consuming, needs to } \\
\text { solve for derivatives of the } \\
\text { electromagnetic field } \\
\text { solution for each parameter } \\
\text { which describes the scatter } \\
\text { profile }\end{array}$ \\
\hline $\begin{array}{l}\text { A three-layer antenna } \\
\text { composed of graphene, } \\
\text { polyamide substrate, and 2D } \\
\text { copper conducting material } \\
\text { [40] }\end{array}$ & $\begin{array}{l}\text { Antenna gain, directivity, } \\
\text { efficiency, plot, return loss } \\
\text { are evaluated }\end{array}$ & $\begin{array}{l}\text { High speed and high } \\
\text { efficiency }\end{array}$ & $\begin{array}{l}737.2 \mathrm{GHz} \\
>5 \mathrm{~mm}\end{array}$ & $\begin{array}{l}\text { Several aspects need to be } \\
\text { considered to evaluate } \\
\text { radiation loss, radiation } \\
\text { efficiency, gain, far-field } \\
\text { characteristics, directivity, } \\
\text { and VSWR }\end{array}$ \\
\hline $\begin{array}{l}\text { Graphene-based antenna for } \\
\text { wearable applications [41] }\end{array}$ & $\begin{array}{l}\text { Different values of substrate } \\
\text { were used for chemical } \\
\text { potential and relaxation time }\end{array}$ & $\begin{array}{l}\text { Large bandwidth and } \\
\text { turnability }\end{array}$ & $\begin{array}{l}5 \mathrm{THz} \\
1 \mathrm{~mm} \sim 2 \mathrm{~mm}\end{array}$ & $\begin{array}{l}\text { The conductivity of copper } \\
\text { metal and skin depth of } \\
\text { humans at THz frequency } \\
\text { results in high propagation } \\
\text { loss \& reduces the radiation } \\
\text { efficiency }\end{array}$ \\
\hline
\end{tabular}




\section{Mobile Communications}

Okabayashi et al. [42] focus on implementing a mobile base station lightning protection by using a combination of $\lambda / 4$ open and $\lambda / 4$ short stub. The mobile phone base stations (MPBS) are composed of antenna towers, which are usually installed on top of the mountains and for this reason, they are most likely to receive lightning strikes, making it necessary to have a lightning protection system. In a lightning protection system, the most significant system is the earth system and bonding network. Computer simulations were performed by injecting lightning strikes into the antenna. Results show that the implemented coaxial surge protective device (SPD) performs efficiently, the antenna components were protected by preventing lightning surges to enter the base transceiver station (BTS) side and it can be applied to different types of wireless devices since it is designed based on the specific frequency. For future research, the authors plan to make a coaxial SPD that operates at higher frequencies by using the same technology as the current system.

Ambalgi et al. [43] focus on designing and implementing a multiple slot patch antenna, it discusses designing the patch and feedline of an antenna which are commonly used in wireless applications. Three types of antennas are designed and compared namely conventional microstrip antenna (CMSA), eight multi-slotted patch having an octagonal slot, square slot, circular slot on patch (EMSPOSCP) and multi slotted patch antenna having hexagonal slots, rhombus slots, square slots on patch (MSPAHRSP). Antenna designs were made using f V15.4 - Integral Three-Dimension Equation (IE3D) EM simulator. The frequency response characteristics of the three designed antennas are studied on Agilent technology E8363 model PNA with frequency ranges from $0.10 \mathrm{MHz}$ to $40 \mathrm{GHz}$. Results show that the radiation pattern of C-MSA is linearly polarized with broadsided nature at 3 $\mathrm{GHz}$ resonance, half power beamwidth $=43$ degrees, gain $=2.1$ $\mathrm{dB}$, it can be useful for indoor communication applications. While EMSPOSCP shows a great improvement of bandwidth (BW) as compared to C-MSA, due to its additional etched patch on the antenna, which leads the antenna to resonate in a wide bandwidth. The EMSPOSCP shows a linearly polarized broadside pattern at $2.8 \mathrm{GHz}$, half power beamwidth $=57$ degrees, gain $=8.31 \mathrm{~dB}$, it can be used in communication band applications. Lastly, the MSPAHRSP has a broadsided radiation with linear characteristics at $9.4 \mathrm{GHz}$, half power beam width $=47$ and 40 degrees and its maximum gain in $\mathrm{BW}$ are $5.64 \mathrm{~dB}, 7.21 \mathrm{~dB}$ and $7.81 \mathrm{~dB}$. It is suitable for applications in $\mathrm{C}$ and $\mathrm{X}$ band frequency range. To conclude, among the three antennas, EMSPOSCP is the most efficient in terms of wireless applications since it was able to achieve a $\mathrm{BW}=1200 \mathrm{MHz}$, return loss $=-43 \mathrm{~dB}$ and gain $=8.39 \mathrm{~dB}$, the improvement in $\mathrm{BW}$ is mainly due to the adding of new multi slots on the proposed antenna.

Barkat et al. [44] focus on implementing a cooperative spectrum (CS) sensing system for cognitive radio (CR) based on the cyclostationary technique. The main signal is modeled using the orthogonal frequency division multiplexing (OFDM) system. The CS sensing system is composed of four main parts namely primary user (PU), the secondary user (SU), sensing channels and communication channels. In this study, the throughput for cooperative sensing, system overhead and frame duration were analyzed. The number of SUs was varied and analyzed in some environments such as sensing accuracy, data rate effects and channel fading of the CR. Computer simulations were performed in testing the proposed system. A total of four different simulations are performed such as throughput versus sensing time for a different number of SUs, throughput versus sensing time for different signal-to-noise ratio (SNR) values, throughput versus the number of SUs, throughput versus traffic intensity for different numbers of SUs. Results show that the relationship between the throughput and sensing time is inversely proportional. There is a remarkable improvement in terms of SU throughput when the parameters for sensing threshold and throughput are optimized together. Also, there is always a tradeoff between the throughput and the number of SUs since a bigger part of the frame is occupied when using more SUs, leading to high throughput. Therefore, it is important to be able to find the ideal number of cooperative SUs.

\section{Conclusion for Comparative Survey}

Based on table 1 and table 2, it can be observed that most applications are very limited in terms of their range. Most of these studies can only have up to less than $5 \mathrm{~mm}$. This is one of the limitations in $\mathrm{THz}$ applications, although $\mathrm{THz}$ is very powerful due to its non-invasive and non-ionizing characteristics. The main goal is to be able to make its distance coverage wider so that it can be applied in more applications, some of the ways to boost the $\mathrm{THz}$ signal is to make use of ultra-massive MIMO communication systems, reflectarray antennas, intelligent surfaces and physical layer distance-aware design.

\section{DISCUSSION OF FINDINGS}

\section{A. Industrial Security Applications}

Table 1 shows a survey on $\mathrm{THz}$ imaging for industrial security applications. The applications include detecting different types of illicit drugs, detecting explosive items such as TNT, and detecting aircraft. For the detection of illicit drugs, [23] explores THz imaging and spectroscopy. Although two drugs seem similar chemically, their absorption spectrum in the $\mathrm{THz}$ frequency is distinctively different. This study performs an experiment using three types of sugar, namely maltose, fructose, and glucose. These samples were put inside express mail service (EMS) envelopes, cardboards, and bubble wraps. The authors obtained results with high efficiency by using spectral imaging despite different samples being mixed and placed inside a thick opaque packaging. The main challenge in drug identification is that it is difficult to identify the drugs since the chemical composition may differ after being mixed with other components. Identification of pure drugs becomes problematic as it has many impurities.

After some researchers achieved high-efficiency results, it can be said that the $\mathrm{THz}$ time-domain spectroscopy is a suitable method that can provide accurate spectral information for sample analysis. For detection of more oversized items 
such as explosives and aircraft, many studies encounter problems like distortions of images, and it takes much time to process the images. Therefore, different methods were applied for the image reconstruction process to improve the image quality. Some researchers take the opportunity of the complex field information of the $\mathrm{THz}$ to further process the single-pixel image by combining the time-resolved image reconstruction and the nonlinear $\mathrm{THz}$ image generation technique to improve the image quality. Reference [28] introduced inverse Fresnel diffraction (IFD) algorithm into a single-pixel imaging system and had a good result. Furthermore, some parameters that need to be considered in evaluating the efficiency include signal-to-noise (SNR) ratio, image acquisition time, and spatial resolution. According to [32], one challenging aspect for MIMO setup is that there may be different delays from each hardware component, leading to unbalanced phases among all the channels.

\section{B. Medical Applications}

Table 2 shows a survey on $\mathrm{THz}$ imaging for medical applications. The applications include detection of human skin, human breath, and body organs for health diagnosis. Several researchers are interested in designing a graphenebased wearable $\mathrm{THz}$ antenna due to its small and thin size and strong conductivity for both heat and electricity. Graphene has a distinctive structure because the electrons can move using minimal resistance. This resistance allows the electricity to move at a faster rate than using metal like the typical antenna. The main challenge for human skin detection is that it is difficult to simulate its structure accurately because of the natural human skin absorption. It consists of blood vessels and pigments distributed in-depth and lacks permittivity measurements in the $\mathrm{THz}$ frequency. Due to the absorptions in the lossy body tissue of the human body, the antenna's efficiency worsens.

Furthermore, researchers usually represent the human skin using two layers of the epidermis and a layer of the dermis. It is observed that the outermost layer of the skin has a higher conductivity. Some parameters to evaluate the $\mathrm{THz}$ system include gain, bandwidth, impedance matching, and antenna size. Besides graphene, CNT was able to attract the attention of many researchers, both have unique electronic and mechanical properties, and they are somehow similar. Their main difference is that graphene is a $2 \mathrm{D}$ single film layer, while CNT looks like a 3D cylinder film. Graphene is highly conductive and very thin, commonly used in chemical sensing and energy storage.

On the other hand, CNTs are lightweight and robust. It is an excellent option to strengthen the composite fibers, commonly implemented in sensors and transistors. In addition, some studies combine CNT and graphene. The proposed method [38] identifies the blood glucose level based on human breath chemical compounds for breath sensing. It was found out that acetone in human breath is highly related to blood glucose. It can be used to identify who has diabetes. The THz system was compared with the currently available GC-MS. It has almost the same efficiency, with lower cost, and is more portable.

\section{Summary of Findings}

Table 3. Summary of Methods Used in both Industrial Security and Medical Applications from 2016 to 2021

\begin{tabular}{|c|c|c|}
\hline Year & $\begin{array}{c}\text { Methods used in Industrial Security } \\
\text { Applications }\end{array}$ & $\begin{array}{l}\text { Methods used in Medical } \\
\text { Applications }\end{array}$ \\
\hline 2016 & $\begin{array}{l}\text { TNT explosives detection using } \mathrm{THz} \\
\text { textile microstrip patch antenna with } \\
\quad \text { denim as a substrate [29] } \\
\text { Applied CS for THz imaging [31] }\end{array}$ & $\begin{array}{l}\text { Analyzes blood glucose based on } \\
\text { chemical composition of human } \\
\text { breath [38] }\end{array}$ \\
\hline 2017 & $\begin{array}{l}\text { Identification of illicit drugs using } \mathrm{THz} \\
\text { spectroscopy and imaging [27] } \\
\text { Dominant scatters for high frequency } \\
\text { vibration in THz radar imaging [30] }\end{array}$ & \\
\hline 2018 & $\begin{array}{l}\text { IR camera for converting THz radiation } \\
\text { into thermal radiation [33] }\end{array}$ & \\
\hline 2019 & & $\begin{array}{l}\text { Hybrid gold and graphene wearable } \\
\text { antenna for body monitoring [34] } \\
\text { Stretchable CNT wearable antenna } \\
\text { for body monitoring [35] } \\
\text { Transmission line matrix method for } \\
\text { bialogical image reconstruction [39] } \\
\text { Graphene-based wearable antenna } \\
\text { for body monitoring [41] }\end{array}$ \\
\hline 2020 & $\begin{array}{l}\text { Combination of CS and IFD for } \\
\text { photoinducted dynamic mask based } \\
\text { reflective THz imaging systems [28] } \\
\text { A combination of ultra-wideband and } \\
\text { sparse MIMO array technique for THz } \\
\quad \text { imaging system [32] }\end{array}$ & $\begin{array}{c}\text { Stretchable polyurethane substrate } \\
\text { and CNT for body liquid quality } \\
\text { detection [37] }\end{array}$ \\
\hline 2021 & & $\begin{array}{l}\text { Graphene, polyamide substrate and } \\
\text { 2D copper conducting material for } \\
\text { medical imaging [40] }\end{array}$ \\
\hline
\end{tabular}

Table 3 shows a summary of the data in tables 1 and 2. It shows both industrial security and medical applications with its corresponding year of study. For industrial security applications, it can be observed that each of the past research reviewed applied different methods and solutions in $\mathrm{THz}$ imaging and spectroscopy. For medical applications, it can be observed that most research from 2016 to 2021 are making wearable body monitoring systems using graphene and CNT.

Figure 5 is a pie chart showing the applied area of $\mathrm{THz}$ application in the field of industrial security [27-33], it is observed that the majority, $57 \%$ applied $\mathrm{THz}$ spectroscopy and imaging in identifying the object for industrial security applications. Among the seven studies, three studies, 43\% applied THz imaging [30, 32-33], while four studies applied THz spectroscopy and imaging [27-29, 31]. 


\section{Applied Area of THz Application in} the Field of Industrial Security

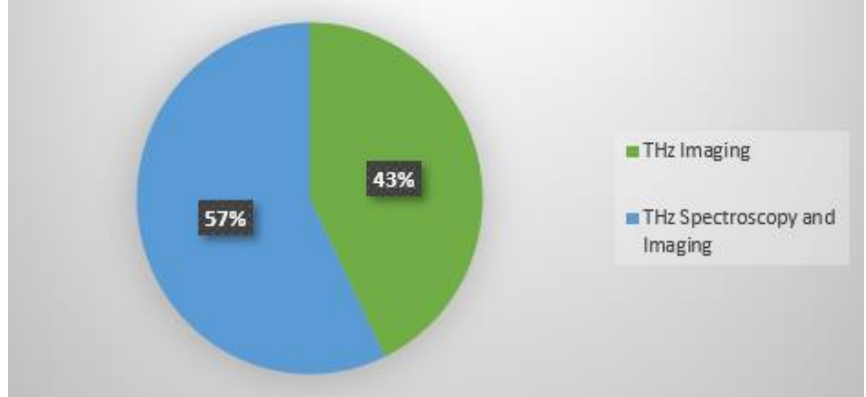

Figure 5. Applied Area of THz Applications in the Field of Industrial Security

Figure 6 is a pie chart showing the applied area of $\mathrm{THz}$ application in the field of medicine [34, 35, 37-41]. Unlike figure 5, figure 6 shows that the majority, $71 \%$ of the medical applications applied THz imaging systems [34, 35, 37, 39, 41] among all the seven studies reviewed for medical applications.

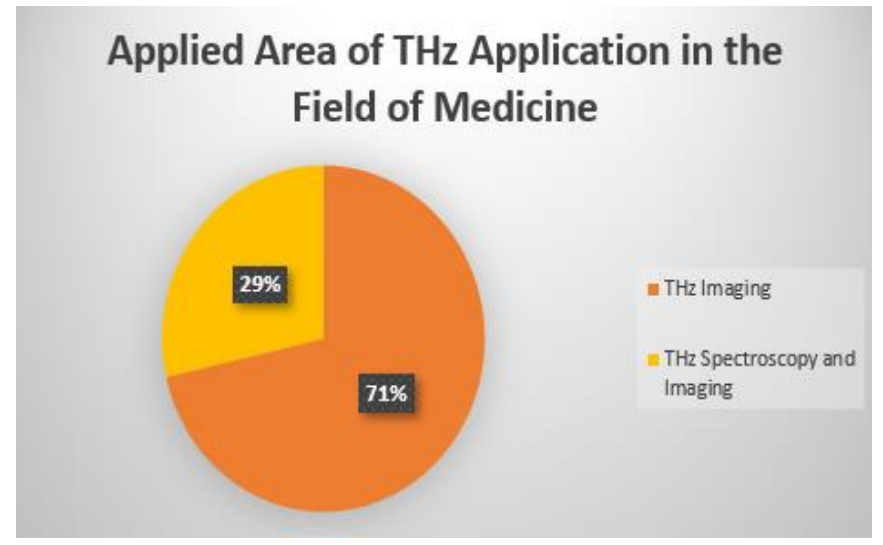

Figure 6. Applied Area of THz Applications in the Field of Medicine

\section{Conclusion for Comparison}

Based on table 3 , figure 5 and figure 6 , a total of 14 previous researches in the field of industrial security and medicine were reviewed and compared. It can be concluded that graphene and CNT technology was able to attract the interest of many researchers for medical applications due to their strong, powerful, flexible and stretchable characteristics. Many of the technology advancements in the $\mathrm{THz}$ band for medical applications develop portable and wearable body monitoring systems, the main goal is to have a portable, lightweight, efficient and low cost. In addition, various types of methods and solutions were done for industrial security applications, but it can be concluded that much research applied $\mathrm{THz}$ spectroscopy and imaging, this is due to the complex composition of some materials such as illicit drugs, artwork or explosives. $\mathrm{THz}$ spectroscopy imaging is a powerful tool since it can detect some chemical properties which cannot normally be seen by using other frequency bands.

\section{OVERALL CONCLUSION}

The author was able to gather literature related to MIMO techniques in the terahertz frequency band. This survey focuses on $\mathrm{THz}$ imaging applications. It was divided into two aspects, namely industrial security applications and medical applications. A total of two survey tables were made, one for industrial security and another for medical applications. The parameters used to compare are vital features, essential techniques, prominent advantages, challenges, distance, and frequency.

The $\mathrm{THz}$ is a section of the electromagnetic radiation between the microwave frequency and IR frequency. It has a frequency range of $0.1 \mathrm{THz}$ to $10 \mathrm{THz}$, with a corresponding wavelength range from $3 \mathrm{~mm}$ to $30 \mu \mathrm{m}$, also known as the $\mathrm{THz}$ gap. $\mathrm{THz}$ waves are noninvasive and nonionizing, meaning they are not harmful to humans and animals, making them highly acceptable for medical applications such as skin and body organ diagnosis. The $\mathrm{THz}$ frequency band is unique because it can look through a wide range of opaque materials such as paper, clothing, plastics, textiles, and cardboard, making it a good candidate for industrial and security applications. Furthermore, the $\mathrm{THz}$ radiation is safe and does not cause harm to the target compared to X-rays. Thus, it is suitable for various imaging and spectroscopy applications. It is a powerful tool for non-destructive inspection. Also, some materials like explosives and chemical compounds have distinctive spectral fingerprints at a frequency between 0.1 $\mathrm{THz}$ to $3 \mathrm{THz}$, which only the $\mathrm{THz}$ radiation can identify.

Moreover, the $\mathrm{THz}$ radiation is sensitive to different types of resonances. It can provide specific information about a particular molecule. On the other hand, some drawbacks of $\mathrm{THz}$ waves are that they are quite sensitive to environmental factors such as rain, thunderstorms, and building obstructions. The scattering and absorption of signals limit its communication range. One solution to this issue is to develop beamforming to make directional beams leading to an improved communication range with minimal interference. Also, increasing the $\mathrm{THz}$ signal strength is possible by making the vertical main lobe precisely align with the receiver position in $3 \mathrm{D}$ beamforming. By applying MIMO systems, spatial separation can be maximized by the alteration of vertical dimension, which can improve the overall signal quality and increase the number of users that can be handled.

To conclude, $\mathrm{THz}$ waves have great potential in many applications. Since the $\mathrm{THz}$ radiation is noninvasive and nonionizing, it is a powerful tool and opens room to be applied in other fields in the near future. Although researchers are working on $\mathrm{THz}$, the study of $\mathrm{THz}$ is still in the infancy stage. The currently available technology is very limited and expensive, making it challenging to apply it practically with a limited budget effectively. Mainly it is due to the extremely high $\mathrm{THz}$ wave, which conventional semiconductor technologies cannot handle.

Furthermore, some problems in $\mathrm{THz}$ imaging which need to be addressed include image resolution, signal-to-noise ratio, and speed acquisition. One way of addressing this issue is to develop a beamforming component for the specific requirements of the $\mathrm{THz}$ system. Since image reconstruction in $\mathrm{THz}$ is time-consuming, a new transmission line matrix 
method combines the node and nonlinear conjugate gradient optimization technique. The object's shape can be acquired and proved efficient for inverse scattering and sensitivity analysis, with high accuracy even if the image is noisy. In addition, graphene-based antennas show great potential for $\mathrm{THz}$ applications since they are powerful, flexible and small, and can be applied in various applications. Also, it is crucial to focus more on the $\mathrm{THz}$ skin detection systems for more advanced and accurate results since its complex absorption behavior makes it hard to obtain an exact diagnosis. Lastly, one should never forget that $\mathrm{THz}$ frequency can be applied in various applications, and numerous researches are being conducted in different fields of science. Therefore, integrating different areas can bring the $\mathrm{THz}$ applications to the next level of high-speed wireless communications.

\section{REFERENCES}

[1] "Learn about Multiple-Input Multiple-Output." Intel, Jun. 15, 2021. Accessed: Jul. 30, 2021. [Online]. Available: https:/www.intel.com/content/www/us/en/support/articles/00 0005714/wireless/legacy-intel-wireless-products.html

[2] H. Gao et al., "Study of the Extended Phase Shift Migration for Three-Dimensional MIMO-SAR Imaging in Terahertz Band," IEEE Access, vol. 8, pp. 24773-24783, 2020, doi: 10.1109/ACCESS.2020.2965189.

[3] A. Faisal, H. Sarieddeen, H. Dahrouj, T. Al-Naffouri, and M.S. Alouini, "Ultra-Massive MIMO Systems at Terahertz Bands." Accessed: Aug. 07, 2021. [Online]. Available: https://www.wwrf.ch/files/content $\% 20$ wwrf/meetings/past $\% 2$ 0events/wwrf43/presentations $\% 20$ wwrf43/Alice\%20Faisal.pd $\mathrm{f}$

[4] A. Krumbein, "Introduction to the Basics of MIMO Communication Technology." SWA, Aug. 10, 2016. Accessed: Jul. 30, 2021. [Online]. Available: https:/www.southwestantennas.com/articles/general-productinformation/introduction-basics-mimo-communicationtechnology

[5] M. Saad, A. C. Al Ghouwaye, H. Hijazi, F. Bader, and J. Palicot, "MIMO Techniques for Wireless Terabits Systems under Sub$\mathrm{THz}$ Channel with RF Impairments," in 2020 IEEE International Conference on Communications Workshops (ICC Workshops), 2020, pp. 1-6. doi: 10.1109/ICCWorkshops49005.2020.9145359.

[6] S. A. Hoseini, M. Ding, and M. Hassan, "Massive MIMO Performance Comparison of Beamforming and Multiplexing in the Terahertz Band," in 2017 IEEE Globecom Workshops (GC Wkshs), 2017, pp. 1-6. doi: 10.1109/GLOCOMW.2017.8269042.

[7] MIMO vs SISO- What's the difference? (n.d.). Steatite. Retrieved November 16, 2021, from https;//www.steatitecommunications.co.uk/mimo-vs-siso/

[8] Shah, C. (2017). Performance and Comparative Analysis of SISO, SIMO, MISO, MIMO. Research India Publications, 9, $1-14$.

[9] E. Webster and N. Media, "MIMO (multiple input, multiple output)." TechTarget. Accessed: Jul. 30, 2021. [Online].Available: https://searchmobilecomputing.techtarget.com/definition/MI MO
[10] "What is MIMO Wireless Technology." ElectronicsNotes. Accessed: Jul. 30, 2021. [Online]. Available: https://www.electronics-notes.com/articles/antennaspropagation/mimo/what-is-mimo-multiple-input-multipleoutput-wireless-technology.php

[11] N. Khiabani, "Introduction to the Terahertz Band." All About Circuits, Sep. 12, 2019. Accessed: Aug. 05, 2021. [Online].Available: https://www.allaboutcircuits.com/technicalarticles/introduction-to-terahertz/

[12] "Medical diagnostics Potential biomedical applications." TeraSense. [Online]. Available: https://terasense.com/applications/medical-diagnostics/

[13] "The future of $\mathrm{THz}$ imaging in medical applications looks promising." May 22, 2018. [Online]. Available: https://www.gentec-eo.com/blog/terahertz-imaging-medicalapplications

[14] L. Yu and L. Hao, "The medical application of terahertz technology in noninvasive detection of cells and tissues: opportunities and challenges." [Online]. Available: https://pubs.rsc.org/en/content/articlelanding/2019/ra/c8ra106 $05 \mathrm{c}$

[15] Wireless Industry's Newest Gambit: Terahertz Communication Bands. (2019). IEEE Spectrum. https://spectrum.ieee.org/wireless-industrys-newest-gambitterahertz-communication-bands

[16] Saeedkia, D. (2013). Optoelectronic techniques for the generation and detection of terahertz waves. Science Direct.https://www.sciencedirect.com/topics/engineering/tera hertz

[17] "Terahertz Technology." 2019. Accessed: Aug. 06, 2021. [Online]. Available: https://terasense.com/terahertztechnology/

[18] K. Tekbıyık, A. R. Ekti, G. K. Kurt, and A. Gorcin, "Terahertz band communication systems: Challenges, novelties and standardization efforts," vol. 35, Aug. 2019, doi: https://doi.org/10.1016/j.phycom.2019.04.014.

[19] T. Suzuki, K. Takayama, S. Yamauchi, Y. Imai, and M. Tonouchi, "Measurement of water absorption coefficient using terahertz time-domain spectroscopy," in 2009 34th International Conference on Infrared, Millimeter, and Terahertz Waves, 2009, pp. 1-2. doi: 10.1109/ICIMW.2009.5325641.

[20] Venckevičius, R., Kašalynas, I., \& Valušis, G. (2016). 'Color' photography at terahertz frequencies. https://spie.org/news/6285-color-photography-at-terahertzfrequencies? $\mathrm{SSO}=1$

[21] Seco-Martorell, C., López-Domínguez, V., Arauz-Garofalo, G., Redo-Sanchez, A., Palacios, J., \& Tejada, J. (2013). Goya's artwork imaging with Terahertz waves. Optica, 21(15), 17800 17805. https://doi.org/10.1364/OE.21.017800

[22] M. He, A. K. Azad, S. Ye, and W. Zhang, "Far-infrared signature of animal tissues characterized by terahertz timedomain spectroscopy," p. 389 to 392

[23] "Advantages of Terahertz (THz) $\mid$ Disadvantages of Terahertz (THz) waves." RF Wireless World. Accessed: Aug. 06, 2021. [Online]. Available: https://www.rfwirelessworld.com/Terminology/Advantages-and-Disadvantages-ofTerahertz-THz-Waves.html

[24] "Terahertz Properties." TOPTICA Photonics. Accessed: Aug. 06, 2021. [Online]. Available: https://www.toptica.com/technology/technicaltutorials/terahertz/terahertz-properties/

[25] I. McAuley, L. Young, M. Gradziel, W. Lanigan, C. O'Sullivan, and J. A. Murphy, "Millimetre-wave and Terahertz Imaging Systems with Medical Applications," presented at the Infrared 
Millimeter Waves and 14th International Conference on Terahertz Electronics.

[26] A. Bandyopadhyay, A. Sengupta, R. B. Barat, D. E. Gary, and J. F. Federici, "Effects of scattering on THz spectra of granular solids," pp. 969-978.

[27] M. O. AlNabooda, R. M. Shubair, N. R. Rishani, and G. Aldabbagh, "Terahertz spectroscopy and imaging for the detection and identification of illicit drugs," in 2017 Sensors Networks Smart and Emerging Technologies (SENSET), 2017, pp. 1-4. doi: 10.1109/SENSET.2017.8125065.

[28] Y. Lu et al., "Reflective Single-Pixel Terahertz Imaging Based on Compressed Sensing," IEEE Transactions on Terahertz Science and Technology, vol. 10, no. 5, pp. 495-501, 2020, doi: 10.1109/TTHZ.2020.2982350.

[29] S. S. Saini, T. K. Gill, P. Kuchroo, and E. Sidhu, "TeraHertz textile microstrip patch antenna design employing denim substrate for detection of TNT explosives," in 2016 International Conference on Control, Computing, Communication and Materials (ICCCCM), 2016, pp. 1-4. doi: 10.1109/ICCCCM.2016.7918241.

[30] Q. Yang, B. Deng, H. Wang, and Y. Qin, "Compensation for high frequency vibration in the terahertz radar imaging based on dominant scatterers," in 2017 10th UK-Europe-China Workshop on Millimetre Waves and Terahertz Technologies (UCMMT), 2017, pp. 1-4. doi: 10.1109/UCMMT.2017.8068516.

[31] L. Liu, Z. Zhang, L. Gan, Y. Shen, and Y. Huang, "Terahertz imaging with compressed sensing," in 2016 IEEE 9th UKEurope-China Workshop on Millimetre Waves and Terahertz Technologies (UCMMT), 2016, pp. 50-53. doi: 10.1109/UCMMT.2016.7873958.

[32] C. Sun, Q. Chang, R. Zhao, Y. Wang, and J. Wang, "Terahertz Imaging Based on Sparse MIMO Array," in 2020 International Conference on Microwave and Millimeter Wave Technology (ICMMT), 2020, pp. 1-3. doi: 10.1109/ICMMT49418.2020.9387009.

[33] A. Salmon, P. Bouchon, S. Rommeluere, P. Fauche, J.-P. Caumes, and R. Haïdar, "Terahertz Multispectral Imaging by Thermo-Conversion using MIM Antenna," in 2018 43rd International Conference on Infrared, Millimeter, and Terahertz Waves (IRMMW-THz), 2018, pp. 1-2. doi: 10.1109/IRMMW-THz.2018.8510419.

[34] A. Abohmra, F. Jilani, H. Abbas, A. Alomainy, M. A. Imran, and Q. H. Abbasi, "Hybrid terahertz antenna design for bodycentric applications," in Antennas and Propagation Conference 2019 (APC-2019), 2019, pp. 1-5. doi: 10.1049/cp.2019.0704.

[35] Y. Tokumoto, K. Li, T. Araki, Y. Harada, T. Sekitani, and Y. Kawano, "Stretchable Terahertz Imagers for Wearable Biomonitoring Applications," in 2019 44th International Conference on Infrared, Millimeter, and Terahertz Waves (IRMMW-THz), 2019, pp. 1-2. doi: 10.1109/IRMMWTHz.2019.8874350.

[36] K. Humphreys et al., "Medical applications of THz imaging: a review of current technology and potential applications in biomedical engineering," in The 26th Annual International Conference of the IEEE Engineering in Medicine and Biology Society, 2004, vol. 1, pp. 1302-1305. doi: 10.1109/IEMBS.2004.1403410.

[37] R. Utaki, K. Li, and Y. Kawano, "A stretchable wideband photo-thermoelectric wrap scanner sheet for wearable and noninvasive liquid quality monitoring," in 2020 45th International Conference on Infrared, Millimeter, and Terahertz Waves (IRMMW-THz), 2020, pp. 1-2. doi: 10.1109/IRMMW-THz46771.2020.9370541.

[38] I. R. Medvedev et al., "Analysis of exhaled human breath via terahertz molecular spectroscopy," in 201641 st International
Conference on Infrared, Millimeter, and Terahertz waves (IRMMW-THz), 2016, pp. 1-2. doi: 10.1109/IRMMWTHz.2016.7758450.

[39] A.-A. I. M. Hassanin, A. S. E. Shaaban, and F. E. Abd ElSamie, "Medical Applications of Image Reconstruction Using Electromagnetic Field in Terahertz Frequency Range," in 2019 International Symposium on Networks, Computers and Communications (ISNCC), 2019, pp. 1-4. doi: 10.1109/ISNCC.2019.8909157.

[40] C. M. Krishna, M. Bhavana, D. Manisha, and T. Neha, "Investigation on Graphene based Terahertz Antenna for Medical Imaging," in 2021 Third International Conference on Intelligent Communication Technologies and Virtual Mobile Networks (ICICV), 2021, pp. 64-69. doi: 10.1109/ICICV50876.2021.9388563.

[41] A. Abohmra, F. Jilani, H. Abbas, M. A. Imran, and Q. H. Abbasi, "Terahertz Antenna based on Graphene for Wearable Applications," in 2019 IEEE MTT-S International Wireless Symposium (IWS), 2019, pp. 1-3. doi: 10.1109/IEEEIWS.2019.8803929.

[42] Okabayashi, C., \& Kijima, H. (2020). Lightning Protection for Mobile Phone Base Stations by combining $\lambda / 4$ short Stub and $\begin{array}{llll}\lambda / 4 & \text { open } & \text { Stub. } & \text { 19, 249-255. }\end{array}$ https://doi.org/10.37394/23204.2020.19.29

[43] Ambalgi, A., K, S., \& Vaish, A. (2020). Experimental and Simulation Study of Effects in Etched Patch Antenna with Multi Slots. 19, 142-148. https://doi.org/10.37394/23204.2020.19.16

[44] Barkat, E. (2020). Throughput Analysis for Cooperative Cognitive Radio Networks using Cyclostationary Detection. 19, 240-248. https://doi.org/10.37394/23204.2020.19.28

\section{Creative Commons Attribution License 4.0 (Attribution 4.0 International, CC BY 4.0)}

This article is published under the terms of the Creative Commons Attribution License 4.0 https://creativecommons.org/licenses/by/4.0/deed.en_US 